\title{
Relapsed and unresectable inflammatory myofibroblastic tumor responded to chemotherapy: A case report and review of the literature
}

\author{
YASUHIRO MARUYAMA ${ }^{1,2}$, TOSHIROU FUKUSHIMA ${ }^{1}$, DAISUKE GOMI ${ }^{1}$, \\ TAKASHI KOBAYASHI ${ }^{1}$, NODOKA SEKIGUCHI ${ }^{1}$, AKIYUKI SAKAMOTO $^{1}$, \\ SHIGERU SASAKI $^{1}$, KEIKO MAMIYA ${ }^{1}$ and TOMONOBU KOIZUMI ${ }^{1}$ \\ ${ }^{1}$ Department of Comprehensive Cancer Therapy and ${ }^{2}$ Second Department of Internal Medicine, \\ Shinshu University School of Medicine, Matsumoto, Nagano 390-8621, Japan
}

Received June 13, 2016; Accepted September 23, 2016

DOI: $10.3892 / \mathrm{mco} .2017 .1383$

\begin{abstract}
A 63-year-old female patient who had undergone cholecystectomy for inflammatory myofibroblastic tumor (IMT) in the gallbladder was referred to our hospital. The patient's disease relapsed, involving the pancreas, and was diagnosed as inoperable IMT 13 months after the cholecystectomy. The patient failed to respond to steroid and non-steroidal anti-inflammatory drug therapy, but subsequently exhibited a good response to vinorelbine and methotrexate combination chemotherapy. Little information is currently available on the efficacy of chemotherapy for adult-onset IMT. The present case suggests that chemotherapy with vinorelbine and methotrexate is a viable therapeutic option for adult patients with unresectable IMT.
\end{abstract}

\section{Introduction}

Inflammatory myofibroblastic tumor (IMT) is a rare disease of unknown etiology (1-3). This tumor was previously described as an inflammatory pseudotumor, inflammatory myofibroblastoma, lymphoplasmacytic histiocytoma and fibrous pseudotumor until 1994, when myofibroblastic tumor was established as a distinct low-grade malignancy by the World Health Organization (1-3). IMT is considered to be a neoplasm of intermediate biological potential, which may recur and metastasizes infrequently (1-4). Histologically, IMT is characterized by myofibroblastic spindle cells mixed with a hyalinized stroma and various degrees of inflammatory infiltrates (1-3). IMT occurs principally in children and young

Correspondence to: Dr Tomonobu Koizumi, Department of Comprehensive Cancer Therapy, Shinshu University School of Medicine, 3-1-1 Asahi, Matsumoto, Nagano 390-8621, Japan E-mail: tomonobu@shinshu-u.ac.jp

Key words: vinorelbine, methotrexate, metastatic pancreatic tumor, unresectable inflammatory myofibroblastic tumor adults (4-10) and may affect any site in the body, although it is most commonly found in the lungs (4-6).

It is well established that total surgical excision is the most effective therapeutic option for surgically accessible IMT (2). However, the treatment options for relapsed and/or inoperable IMT are extremely limited due to the lack of reports regarding effective treatments. In particular, little evidence has been reported in the literature regarding the efficacy of chemotherapy for IMT (7-14). We encountered a case of inoperable IMT with pancreatic involvement following cholecystectomy for IMT originating from the gallblabber. The patient failed to respond to non-steroidal anti-inflammatory drugs (NSAIDs) and steroid therapy, but subsequently showed a good response to vinorelbine (VNB) and methotrexate (MTX) combination chemotherapy. We herein describe the clinical course and present a review of the literature on the effectiveness of chemotherapy for advanced and unresectable IMT.

\section{Case report}

A 63-year-old woman with no significant past medical history was admitted to a local hospital with the complaint of abdominal fullness and pain. A tumor was detected in the gallbladder, and the patient underwent surgical resection. Distant metastasis or invasion into adjacent organs were not observed based on radiographic findings prior to the operation and intraoperative inspection. The pathological diagnosis was IMT (Fig. 1). Thirteen months following resection, tumors in the pancreatic head and tail (Fig. 2A) were identified on whole-body computed tomography (CT) during postoperative follow-up. The patient was subsequently referred to the Department of Comprehensive Cancer Therapy, Shinshu University School of Medicine (Matsumoto, Japan) for further examination. Positron emission tomography with ${ }^{18}$ F-fluorodeoxyglucose (FDG-PET) revealed abnormal uptake by both tumors. Endoscopic examination revealed a submucosal tumor in the duodenum (Fig. 2B). Endoscopic ultrasound-guided fine-needle aspiration in the pancreatic head tumor was performed and the histological diagnosis was recurrence of IMT (Fig. 3). The histological findings 

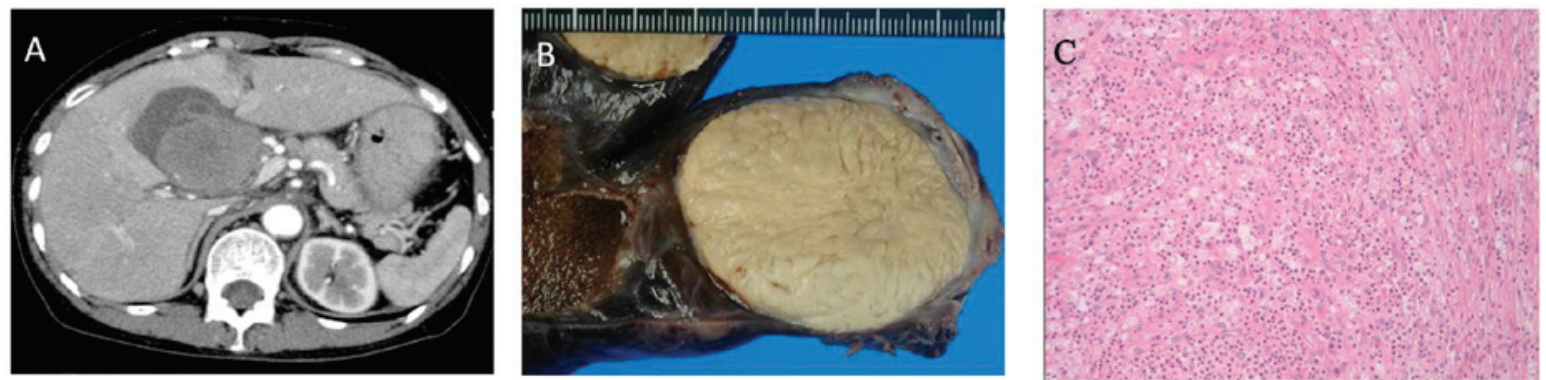

Figure 1. (A) Abdominal computed tomography findings at initial presentation in the present case. A gallbladder tumor was detected prior to the operation. (B) Macroscopically, the resected tumor was a multinodular tan mass with a fleshy surface on cross-section. (C) The histological findings on hematoxylin and eosin staining showed proliferation of myofibroblastic spindle cells with lymphoplasmacytic inflammatory infiltrates. These findings were consistent with the diagnosis of inflammatory myofibroblastic tumor.
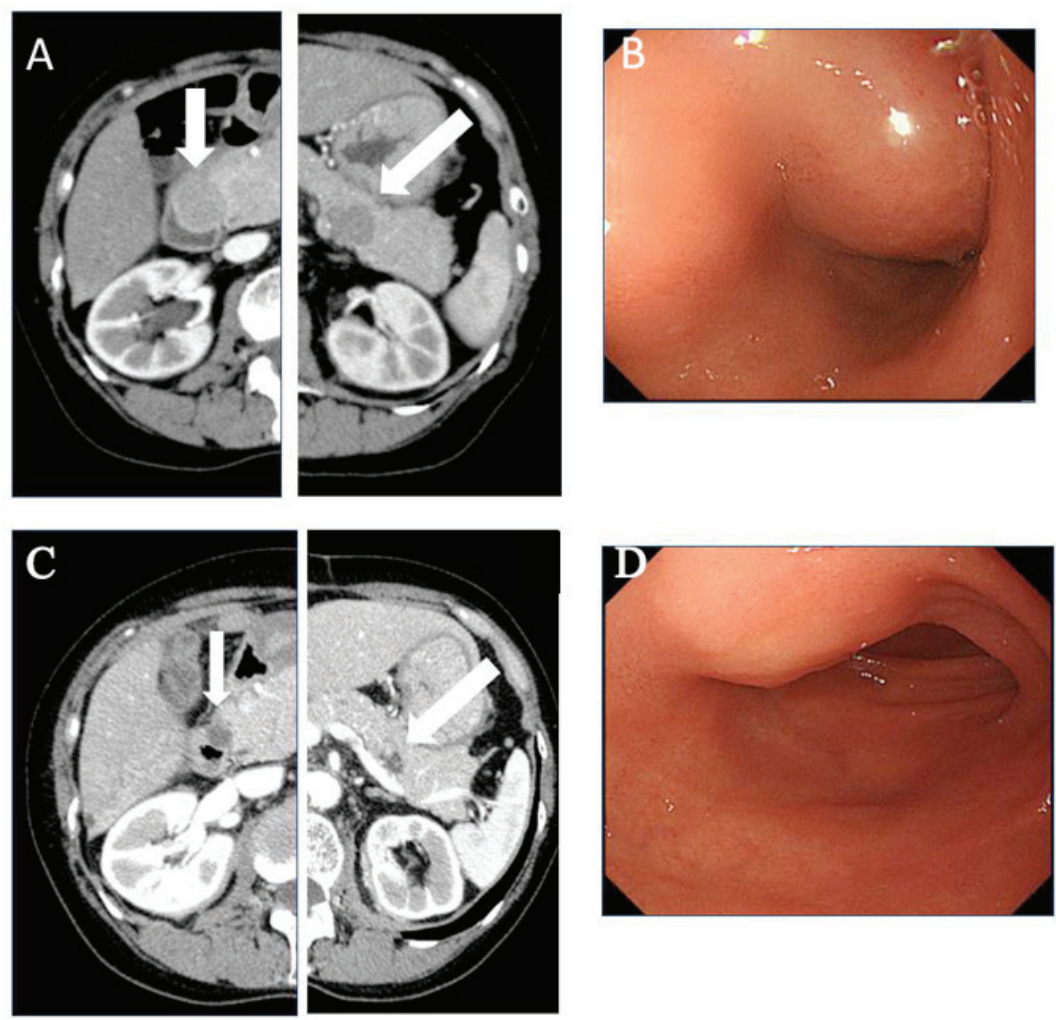

Figure 2. (A) Abdominal computed tomography (CT) showed pancreatic head and tail tumors and (B) endoscopic examination revealed a submucosal tumor in the duodenum prior to chemotherapy. The (C) abdominal CT and (D) endoscopic findings after 6 cycles of chemotherapy revealed that the pancreatic tumors in the head and tail of the pancreas had shrunk following vinorelbine and methotrexate chemotherapy.

and molecular analysis of specimens collected from the pancreas and gallbladder revealed no pathological evidence of malignancy. In addition, there was no presence of anaplastic lymphoma kinase (ALK) protein by immunohistochemical staining or gene rearrangement by fluorescence in situ hybridization. Treatment with NSAIDs and methylprednisolone (500 mg/dayx 3 day, intravenously) followed by $1 \mathrm{mg} / \mathrm{kg}$ of prednisolone for 1 month was continued, but the tumors were not reduced in size. Subsequently, treatment with methotrexate (MTX; $30 \mathrm{mg} / \mathrm{m}^{2}$ on day 1) plus vinorelbine (VNB; $20 \mathrm{mg} / \mathrm{m}^{2}$ on days 1 and 7) per 3 weeks chemotherapy was administered. The chemotherapy was continued without any severe toxicities. The dosage was repeated six times and partial response was achieved as determined by $\mathrm{CT}$ and endoscopic examination (Fig. 2C and D).

\section{Discussion}

We herein describe a case of abdominal IMT that developed in an elderly female and responded well to VNB and MTX chemotherapy. IMT is usually encountered in children and adolescents, mostly occurring between 2 and 16 years of age and mainly involving the lungs (1-3). Kovach et al (4) summarized 44 cases of IMT in their institutes and reported a mean age of 44 years, ranging from 9 to 88 years. In addition, the tumor location included several extrapulmonary lesions in addition to the lung (4). The patient reported herein had abdominal IMT and was aged 63 years. The association between age of onset and the involved location of IMT remains unclear. However, it has been suggested that recurrence was more common if the lesions were extrapulmonary (4). 
Table I. Previous case reports successfully treated with cytotoxic chemotherapy.

\begin{tabular}{|c|c|c|c|c|c|c|c|}
\hline Case & $\begin{array}{l}\text { Age, } \\
\text { years }\end{array}$ & Location & Agent/regimen & Response & NSAIDs & Surgery & (Refs.) \\
\hline 1 & 7 & Abdomen & $\begin{array}{l}\text { Vincristine+etoposide } \rightarrow \text { cisplatin, } \\
\text { adriamycin, methotrexate }\end{array}$ & PR & + & + & $(8)$ \\
\hline 2 & 10 & Abdomen & $\begin{array}{l}\text { Methotrexate+vinblastine, adriamycin, } \\
\text { ifosfamide }\end{array}$ & PR & & + & (9) \\
\hline 3 & 12 & Conjuctiva & Methotrexate+vinorelbine & PR & & & $(10)$ \\
\hline 4 & 14 & Peritoneum & Cisplatin+methotrexate & $\mathrm{CR}$ & + & + & (11) \\
\hline 5 & 26 & Mediastinum & Carboplatin+paclitaxel & $\mathrm{CR}$ & & & $(12)$ \\
\hline 6 & 64 & Frontal bone & Methotrexate & PR & + & & (13) \\
\hline 7 & 64 & Abdomen & Doxorubicin+ifosfamide & PR & & & (14) \\
\hline
\end{tabular}

PR, partial response; CR, complete response; NSAIDs, non-steroidal anti-inflammatory drugs.
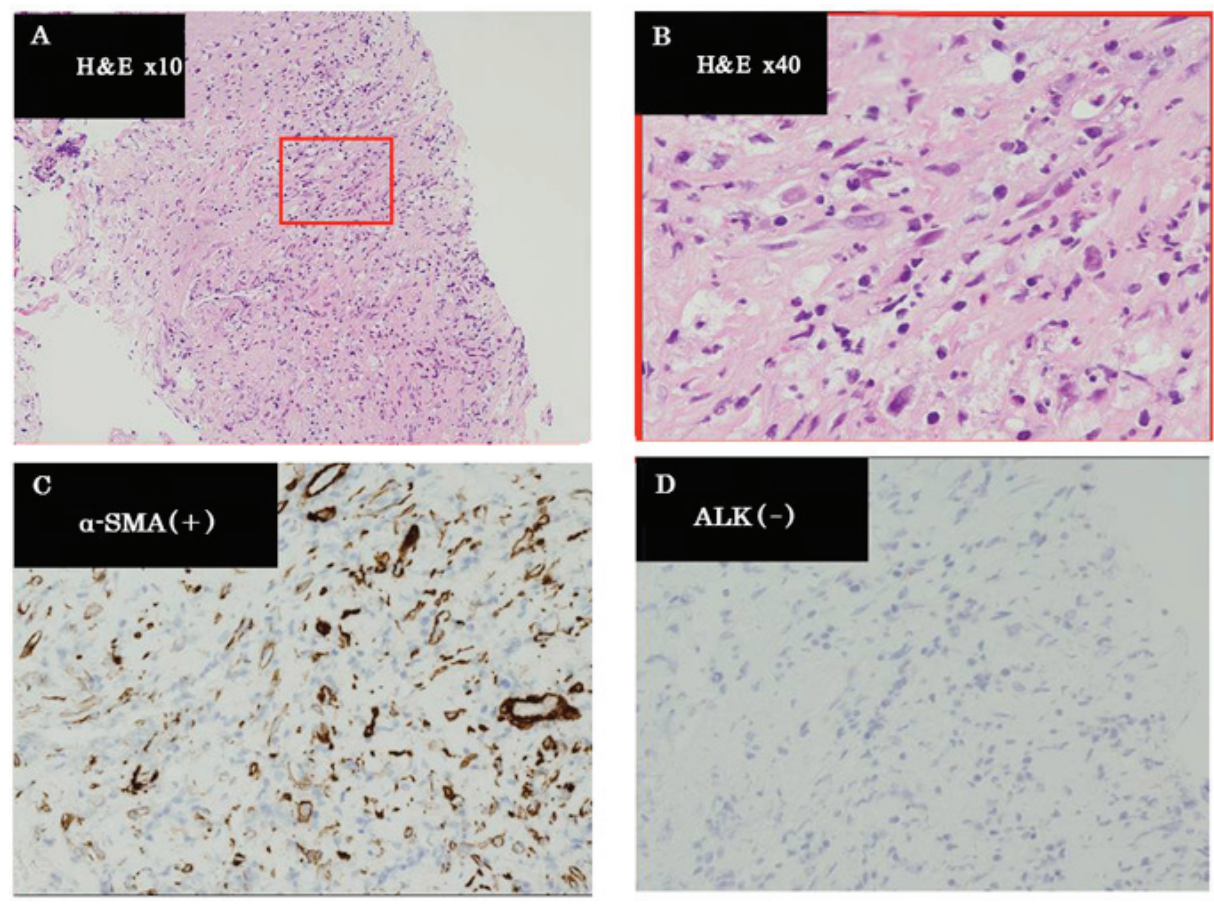

Figure 3. (A and B) The histological findings of specimens collected from the pancreatic tumor revealed a relapsed inflammatory myofibroblastic tumor [hematoxylin and eosin (H\&E) staining]. Immunohistochemical examination showed (C) positive staining for $\alpha$-smooth muscle actin (SMA) and (D) negative staining for anaplastic lymphoma kinase (ALK).

Although our patient had an ALK-negative tumor, it has been demonstrated that $\sim 50 \%$ of IMTs harbor ALK gene rearrangement $(2,15)$. Coffin et al (2) analyzed 59 IMTs and reported that ALK-negative IMTs had a more aggressive clinical course with a high risk of distant metastasis. In addition, the absence of ALK expression was associated with older age (2). Thus, clinical manifestations, including age, location and ALK negativity in the present case were consistent with those reported in the literature.

Surgical resection has been considered the preferred treatment for IMT, and may also be used to confirm this diagnosis $(2,16)$. However, IMT is considered to be a neoplasm of intermediate biological potential, which may recur and metastasize, although infrequently (1-4). In unresectable cases, radiotherapy and chemotherapy, including steroids and NSAIDs, were applied (7-14,17,18). Indeed, several clinical reports indicated the usefulness of steroids and NSAIDs $(11,13,17,18)$, although both failed to shrink the tumor in the present case. Various cytotoxic agents or regimens, including MTX, VNB, vincristine, cyclophosphamide, doxorubicin, 5-fluorouracil, cisplatin, carboplatin, paclitaxel, ifosfamide and etoposide, have been used. However, due to the rarity of IMT, the availability of data regarding the efficacy of cytotoxic chemotherapeutic agents is limited. Previously reported treatment regimens, consisting of cytotoxic chemotherapy alone or in combination with NSAIDs, that were found to be effective for IMT are summarized in Table I. However, none of the chemotherapeutic regimens had been 
evaluated in a case series. In addition, the majority of data were obtained from pediatric populations. Thus, there is still a lack of definitive clinical evidence, particularly for adults. As Favini et al (10) reported a case of IMT that responded to VNB plus MTX, this chemotherapy regimen was used in the present case. Chemotherapy was performed without any severe toxicities and the patient responded well. Although the efficacy of this chemotherapy was evaluated in aggressive fibromatosis in cases series $(19,20)$, our experience, including the case reported by Favini et al (10), may provide a treatment choice for patients with unresectable IMT. With regard to other optimal regimens, Kubo et al (12) described the case of an adult IMT patient (aged 26 years) who responded to carboplatin+paclitaxel chemotherapy. As this combination is the most commonly used chemotherapy regimen in various malignancies, carboplatin+paclitaxel may be an optimal choice for adult and inoperable IMT. An optimal agent or combination chemotherapy has not yet been determined for unresectable IMT. Further clinical experience and studies are required to determine the usefulness of chemotherapy for inoperable IMT.

In summary, our observations in the present case suggest that intermediate-dose chemotherapy using vinorelbine and methotrexate is a feasible therapeutic option in adult patients with unresectable IMT.

\section{References}

1. Fletcher CDM, Unni KK, Mertens F (eds): Inflammatory myofibroblastic tumor. In: World Health Organization Classification of Tumours. Pathology and Genetics of Tumours of Soft Tissue and Bone. IARC Press, Lyon, pp91-93, 2002.

2. Coffin CM, Hornick JL and Fletcher CD: Inflammatory myofibroblastic tumor: Comparison of clinicopathologic, histologic, and immunohistochemical features including ALK expression in atypical and aggressive cases. Am J Surg Pathol 31: 509-520, 2007.

3. Mergan F, Jaubert F, Sauvat F, Hartmann O, Lortat-Jacob S, Révillon Y, Nihoul-Fékété C and Sarnacki S: Inflammatory myofibroblastic tumor in children: Clinical review with anaplastic lymphoma kinase, Epstein-Barr virus, and human herpesvirus 8 detection analysis. J Pediatr Surg 40: 1581-1586, 2005.

4. Kovach SJ, Fischer AC, Katzman PJ, Salloum RM, Ettinghausen SE, Madeb R and Koniaris LG: Inflammatory myofibroblastic tumors. J Surg Oncol 94: 385-391, 2006.

5. Coffin CM,Watterson J,Priest JR and DehnerLP: Extrapulmonary inflammatory myofibroblastic tumor (inflammatory pseudotumor). A clinicopathologic and immunohistochemical study of 84 cases. Am J Surg Pathol 19: 859-872, 1995.

6. Tunçözgür B, Ustünsoy H, Bakir K, Uçak R and Elbeyli L: Inflammatory pseudotumor of the lung. Thorac Cardiovasc Surg 48: 112-113, 2000
7. Sanders BM, West KW, Gingalewski C, Engum S, Davis M and Grosfeld JL: Inflammatory pseudotumor of the alimentary tract: Clinical and surgical experience. J Pediatr Surg 36: 169-173, 2001.

8. Dishop MK, Warner BW, Dehner LP, Kriss VM, Greenwood MF, Geil JD and Moscow JA: Successful treatment of inflammatory myofibroblastic tumor with malignant transformation by surgical resection and chemotherapy. J Pediatr Hematol Oncol 25: 153-158, 2003.

9. Bertocchini A, Lo Zupone C, Callea F, Gennari F, Serra A, Monti L and de Ville de Goyet J: Unresectable multifocal omental and peritoneal inflammatory myofibroblastic tumor in a child: Revisiting the role of adjuvant therapy. J Pediatr Surg 46: e17-e21, 2011.

10. Favini F, Resti AG, Collini P, Casanova M, Meazza C, Trecate G and Ferrari A: Inflammatory myofibroblastic tumor of the conjunctiva: Response to chemotherapy with low-dose methotrexate and vinorelbine. Pediatr Blood Cancer 54: 483-485, 2010.

11. Tao YL, Wang ZJ, Han JG and Wei P: Inflammatory myofibroblastic tumor successfully treated with chemotherapy and nonsteroidals: A case report: World J Gastroenterol 18: 7100-7103, 2012

12. Kubo N, Harada T, Anai S, Otsubo K, Yoneshima Y, Ijichi K, Koga T, Takayama K and Nakanishi Y: Carboplatin plus paclitaxel in the successful treatment of advanced inflammatory myofibroblastic tumor. Intern Med 51: 2399-2401, 2012.

13. Kusunoki-Nakamoto F, Matsukawa T, Tanaka M, Miyagawa T, Yamamoto T, Shimizu J, Ikemura M, Shibahara J and Tsuji S: Successful treatment of an unresectable inflammatory myofibroblastic tumor of the frontal bone using a cyclooxygenase-2 inhibitor and methotrexate. Intern Med 52: 623-628, 2013.

14. Inadomi K, Kumagai H, Takayoshi K, Ariyama H, Kusaba H, Nishie A, Yamamoto H, Takase K, Tanaka M, Sagara K, et al: Successful combination chemotherapy for metastatic inflammatory myofibroblastic tumor: A case report. Oncol Lett 10: 2981-2985, 2015.

15. Butrynski JE, D'Adamo DR, Hornick JL, Dal Cin P, Antonescu CR, Jhanwar SC, Ladanyi M, Capelletti M, Rodig SJ, Ramaiya N, et al: Crizotinib in ALK rearranged inflammatory myofibroblastic tumor. N Engl J Med 363: 1727-1733, 2010;

16. Janik JS, Janik JP, Lovell MA, Hendrickson RJ, Bensard DD and Greffe BS: Recurrent inflammatory pseudotumors in children. J Pediatr Surg 38: 1491-1495, 2003.

17. Berger A, Kim C, Hagstrom N and Ferrer F: Successful preoperative treatment of pediatric bladder inflammatory myofibroblastic tumor with anti-inflammatory therapy. Urology 70 : 372. e13-e15, 2007.

18. Chan PW, Omar KZ and Ramanujam TM: Successful treatment of unresectable inflammatory pseudotumor of the lung with COX-2 inhibitor. Pediatr Pulmonol 36: 167-169, 2003.

19. Azzarelli A, Gronchi A, Bertulli R, Tesoro JD, Baratti D, Pennacchioli E, Dileo P, Rasponi A, Ferrari A, Pilotti S and Casali PG: Low-dose chemotherapy with methotrexate and vinblastine for patients with advanced aggressive fibromatosis. Cancer 92: 1259-1264, 2001.

20. Meazza C, Bisogno G, Gronchi A, Fiore M, Cecchetto G, Alaggio R, Milano GM, Casanova M, Carli M and Ferrari A: Aggressive fibromatosis in children and adolescents: The Italian experience. Cancer 116: 233-240, 2010. 